\title{
Hamsa
}

H凮MSA Journal of Judaic and Islamic Studies

$6 \mid 2020$

Varia

\section{O «Fundamento da nossa Nação»: A Educação na Comunidade Portuguesa de Hamburgo na segunda metade do Século XVII}

\section{Hugo Martins}

\section{(2) OpenEdition \\ Journals}

Edição electrónica

URL: https://journals.openedition.org/hamsa/292

DOI: 10.4000/hamsa.292

ISSN: 2183-2633

Editora

CIDEHUS - Centro Interdisciplinar de História Culturas e Sociedades da Universidade de Évora

Refêrencia eletrónica

Hugo Martins, «O «Fundamento da nossa Nação»: A Educação na Comunidade Portuguesa de Hamburgo na segunda metade do Século XVII», Hamsa [Online], 6 | 2020, posto online no dia 30 abril 2020, consultado o 13 maio 2021. URL: http://journals.openedition.org/hamsa/292 ; DOI: https:// doi.org/10.4000/hamsa.292

Este documento foi criado de forma automática no dia 13 maio 2021.

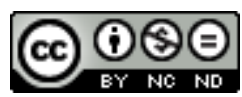

Hamsa est mise à disposition selon les termes de la Licence Creative Commons Attribution - Pas d'Utilisation Commerciale - Pas de Modification 4.0 International. 


\title{
0 «Fundamento da nossa Nação»: A Educação na Comunidade Portuguesa de Hamburgo na segunda metade do Século XVII
}

\author{
Hugo Martins
}

\section{Introdução}

1 Utilizando como fonte os livros protocolares da comunidade judaico-portuguesa de Hamburgo redigidos entre 1652 e $1682,{ }^{1}$ o presente artigo tem como objetivo a investigação e análise das instituições educativas da referida comunidade ao longo das três décadas consideradas: desde os anos iniciais da congregação geral Bet Israel até à sua maturidade institucional, no último terço do século XVII. Fundada por imigrantes portugueses da metrópole e, em menor parte, por exilados de Antuérpia, no seguimento do bloqueio de 1594, a comunidade judaico-portuguesa Hamburgo, viria a servir como um dos principais entrepostos de produtos coloniais no norte da Europa. ${ }^{2}$ Embora as suas atitudes face ao judaísmo fossem de início ambíguas, o pequeno grupo de famílias cristã-novas viria a assumir progressivamente a sua identidade judaica ao longo da primeira década do século XVII, facto que precipitaria, por parte da população local, a exigência de contrapartidas financeiras para a sua permanência na cidade. ${ }^{3}$ Celebrado em 1612, o primeiro contrato de residência com as autoridades estatais intimava os portugueses a viverem modestamente em troca do direito de comerciarem na cidade e de conduzirem transações financeiras dentro do seu limite. ${ }^{4}$ Embora a prática do judaísmo estivesse vedada até pelo menos 1650 , casas privadas foram utilizadas como sinagogas desde pelo menos 1610, dando origem à formação de três congregações distintas: Talmud Torah, Keter Torah, Neve Shalom ${ }^{5}$. Uma quarta congregação, de nome Magen David, juntar-se-lhe-ia ainda antes de 1650. 
2 Beneficiando do embargo ibérico à Holanda entre 1621 e 1641, Hamburgo passaria a ser o principal entreposto ligando a Península Ibérica ao norte da Europa. ${ }^{6}$ Em resultado desta conjuntura favorável e da nova posição proeminente no comércio colonial, a comunidade portuguesa receberia a partir de 1619-22, um considerável impulso económico e demográfico, que se ficaria a dever em grande parte à emigração de muitas das principais famílias portuguesas de Amesterdão para Hamburgo. ${ }^{7}$ De forma a fazer face ao influxo de migrantes, assim como ao crescente número de pobres no seu seio, a comunidade sofre uma profunda reorganização em 1652, unindo as quatro congregações existentes numa única congregação geral denominada Bet Israel. ${ }^{8} \mathrm{O}$ período que se inicia em 1650 e que se estende sensivelmente até meados de 1670 corresponde assim, indiscutivelmente, ao momento de maior prosperidade económica

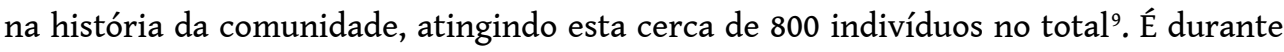
este período igualmente que vários dos seus membros exercem uma vasta influência na política europeia, na condição de agentes diplomáticos, correspondentes e banqueiros internacionais. ${ }^{10} \mathrm{O}$ impressionante sucesso comercial atingido pela comunidade portuguesa de Hamburgo permitiu, por outro lado, o florescimento de uma rica e produtiva vida cultural, a qual se refletiu, em particular, na constituição de bibliotecas privadas de renome internacional ${ }^{11}$.

3 A longo prazo porém, sérias limitações na construção de uma sinagoga geral revelar-seiam cruciais para a perda de atratividade regional exercida pela comunidade enquanto centro de liberdade religiosa e social. ${ }^{12} \mathrm{~A}$ juntar ao crescente assédio clerical instigado por pastores luteranos e problemas sociais internos resultantes do fervor messiânico de 1665-67, a deterioração da conjuntura económica e financeira da cidade levaria a um gradual declínio demográfico a partir de inícios de 1670, resultando na emigração de muitas famílias para Amesterdão. ${ }^{13}$ Finalmente, a celebração em 1697 de um novo contrato altamente prejudicial para os interesses portugueses viria ditar o princípio do fim da comunidade de Hamburgo, coincidindo a sua implementação com a saída de algumas das mais importantes famílias da comunidade, entre as quais os Teixeira, os Nunes Henriques, os Soares e os Bravo. ${ }^{14}$ Embora, para todos os efeitos, a comunidade subsistisse bem para lá deste ponto até ao século XX, a sua influência económica, cultural e social seria, na melhor das hipóteses, marginal, nunca mais recuperando a importância que a definira durante grande parte do século XVII.

\section{Modelo Educativo sefardita - origens e particularidades}

4 Definida como o "fundamento da nossa Nação", a liderança da comunidade judaicoportuguesa de Hamburgo ${ }^{15}$ concedeu grande importância à educação das suas crianças, definindo-a em várias ocasiões como a sua maior obrigação: a única que, mais do que qualquer outra, garantiria o seu sustento no futuro ("Sendo a maior [misva] que temos entre nós, e aquela que mais que todas pode neste nosso cativeiro sustentar-nos"). ${ }^{16}$ Nesse sentido o modelo educativo adotado em Hamburgo seguiu, em traços gerais, o padrão curricular e educacional já adotado na comunidade irmã de Amesterdão, cujo reconhecido sucesso levou-o a ser exportado e implementado nas restantes comunidades da diáspora sefardita ocidental e adaptado às circunstâncias específicas locais. 
5 Em suma, a organização do currículo escolar em Amesterdão obedecia a uma regimentação precisa, encontrando-se dividida em seis níveis distintos, cada um vocacionado a uma idade específica. ${ }^{17}$ Levada a cabo pelos robissim, os professores contratados pela comunidade, a instrução centrava-se em torno da educação religiosa, nomeadamente na lei e tradição judaica, sendo complementada pelo ensino da matemática, da retórica, e da filosofia, assim como por uma vasta oferta de línguas, entre as quais o português, o francês, o espanhol e o latim..$^{18}$ Passada a instrução primária obrigatória, os estudos culminavam então na yeshiva Ets Haim, instituição que proporcionava formação avançada aos que pretendessem seguir a via académica. Outras formas de administração do conhecimento tinham lugar nas irmandades e academias, assim como através de livros e sermões, particularmente entre os adultos. ${ }^{19}$ A eficácia pedagógica deste sistema, comprovada tanto por relatos coevos como pela alta qualidade dos seus discípulos sugere assim, acima de tudo, o pressuposto da coesão transcomunitária da Nação Portuguesa, refletindo tanto a sua partilhada herança cultural, como o desejo de projetar um futuro comum e unificador.

6 O desenvolvimento do modelo escolar utilizado nas comunidades portuguesas da diáspora sefardita ocidental deve a sua origem, tal como sugerido nas últimas linhas, à inovação pedagógica e institucional impulsionada pelo movimento do humanismo renascentista. À semelhança do resto da Europa, a receção dos ideais humanistas entre a cultura letrada portuguesa, em particular a burguesia e certas secções da nobreza e do clero, seriam determinantes para um aumento do número de escolas no país, sobretudo a partir do século XVI. ${ }^{20}$ Refletindo a transição da orientação escolástica medieval para os novos conceitos pedagógicos difundidos por Erasmo e outros educadores, a adaptação do currículo escolar no sentido de uma maior ênfase nas humanidades e no estudo de disciplinas seculares deve entender-se no contexto da emergência de toda uma nova classe de profissionais ligados quer à indústria, ao comércio, às profissões liberais, como ao aparelho de estado, na altura em clara expansão (funcionários públicos, advogados, notários).

7 No centro desta vaga modernizadora encontravam-se os jesuítas, cujo impacto na produção e difusão do conhecimento foi apenas igualado na sua singular e inovadora conceção pedagógica. Mesclando o antigo sistema medieval universitário com os novos colégios de ímpeto reformista, a atuação jesuítica no plano educacional foi marcada em particular pela homogeneização, burocratização e profissionalização do sistema educativo moderno, assim como pela introdução de novas metodologias centradas no conteúdo, forma e impacto da atividade educativa. ${ }^{21}$ Altamente influentes, tais conceitos encontrariam a sua derradeira expressão no Ratio Studiorum (1599), um compêndio de regras práticas para a administração da atividade educativa, cujo comprovado sucesso tanto a nível pedagógico como institucional resultaria na sua emulação como paradigma máximo da didática religiosa contemporânea. ${ }^{22}$

8 Lado a lado com os desenvolvimentos institucionais, surge toda uma nova literatura destinada a educar as crianças e a moldar tanto a sua formação intelectual como atividades sociais. Obras como o popular Colloquia $(1538)^{23}$, escritas pelo humanista Juan Luís Vives tinham como propósito a inculcação da moral cristã nas crianças, indo beber a sua inspiração a Erasmo de Roterdão. Representativas de um novo estilo literário designado de diálogos didáticos, tais obras efetivamente simbolizavam a transição para um novo paradigma na conceção da infância no período moderno, o qual, tal como 
mencionaria Philippe Ariès no seu seminal estudo, seria caracterizado pela identificação nas crianças de uma necessidade educativa específica. ${ }^{24}$

9 A nível literário, indícios de tais preocupações entre os judeus portugueses podem ser encontradas, ainda que esporadicamente, na forma de conselhos e orientações paternas ao estilo dos "testamentos éticos", tais como o deixado por Matatia Aboab aos seus filhos ${ }^{25}$, ou ainda nos escritos de Menasseh Ben Israel, em particular o Thesovro dos Dinim $(1647)^{26}$.

10 Para além da herança cultural ibérica, a organização da vida religiosa que teve lugar em Hamburgo foi fortemente moldada pelos valores, ideias e perceções resultantes tanto da tradição milenar judaica como da sociedade protestante envolvente. Efetivamente, se por um lado a educação era fundamentalmente judaica, apresentando características e traços que a distinguiam como tal (exclusão das mulheres no ensino congregacional), ${ }^{27}$ por outro, evidenciava um paralelismo assinalável com várias instituições homólogas não-judaicas. Prova disso encontra-se, por exemplo, no regimento das escolas primárias sefarditas de Amesterdão e Hamburgo: enquanto alguns aspetos do seu modelo educacional ecoavam inovações jesuítas (em particular o sistema de castigos e recompensas), toda uma gama de práticas como a inspeção regular, o sistema de vigilância e a relação estreita entre o culto e a educação parecem espelhar as atividades disciplinares e didáticas em uso nos consistórios calvinistas da época. Dadas as evidências de interações em outros domínios da administração institucional, tais como o controlo disciplinar e a organização da assistência social. ${ }^{28}$ torna-se assim cada vez mais provável a tese avançada por Heinz Schilling de uma hipotética osmose cultural entre ambas as comunidades, tanto no caso de Amesterdão como no de Hamburgo. ${ }^{29}$

Em traços gerais, o modelo educativo criado e consolidado pelas comunidades portuguesas de "novos judeus" foi o produto muito particular da confluência de várias tradições culturais e religiosas, assim como das vicissitudes específicas da reorganização institucional, expectativas religiosas e fermento intelectual que moldaram o processo de integração dos cristãos-novos no mundo judaico após o seu estabelecimento na Europa do norte..$^{30}$ Porém, se é verdade que o modelo educacional praticado nas comunidades portuguesas partilhava as mesmas características fundamentais, há contudo a destacar importantes variações a nível local, derivadas do contexto formativo em que estas se desenvolveram. Os próximos capítulos vão procurar entender de que forma a educação na comunidade portuguesa de Hamburgo refletiu o ambiente cultural, social e religioso envolvente, particularmente nas suas respostas pragmáticas e institucionais.

\section{Estatutos da Talmud Torah - a Escola elementar da Nação}

Com o intuito de harmonizar a coordenação de todas as partes envolvidas na educação dos jovens, os líderes da comunidade portuguesa definiram no decreto de 17 de Novembro de 1652 os estatutos fundadores da recém-criada Talmud Torah, estabelecendo assim, escrupulosamente, os princípios orientadores da nova instituição e as tarefas a serem observadas por todos os seus intervenientes: alunos, pais, robissim e parnassim..$^{31}$ Reconhecendo os desafios colocados pela experiência negativa no período anterior à unificação da comunidade, o novo regulamento destinava-se a cobrir quatro áreas consideradas críticas na gestão na nova instituição, a saber: 1) a definição de 
horários e currículos de ensino, bem como das regras relativas à profissão de professor, as suas obrigações e o limite da sua autoridade; 2) definição de medidas preventivas visando regular a relação entre pais e professores; 3) a definição de normas comportamentais, das medidas disciplinares e das políticas de incentivo a serem seguidas tanto para alunos, como para professores, e por fim, 4) a criação de um organismo máximo constituído por dois parnassim destinado a supervisionar o cumprimento das regras, reportar eventuais falhas, e assegurar o adequado funcionamento da instituição. ${ }^{32}$

13 No topo da hierarquia administrativa da Talmud Torah encontravam-se os parnassim (administradores ou diretores) eleitos anualmente pelo Mahamad, cuja tarefa era gerir e supervisionar o funcionamento da escola e certificar-se de que as expectativas em relação ao progresso dos estudantes fossem satisfeitas, tanto em termos da sua realização académica como da sua conduta disciplinar. Os parnassim eram assim os principais intermediários entre o Mahamad e a escola e, como tal, eram incumbidos de relatar ao último todos os assuntos de particular relevância que tivessem a ver com a administração da Talmud Torah. Contrariamente, quando o Mahamad tinha razões para suspeitar de uma supervisão deficiente por parte dos parnassim, convocava o conselho de administradores recordando-lhes as suas responsabilidades e deveres assumidos nos estatutos da instituição. ${ }^{33}$

o programa curricular da Talmud Torah dividia-se em quatro níveis, cada um atribuído a um diferente professor. O primeiro - a lição de "alef Bet ate comesso de perassa" - foi atribuída ao professor R. Mose Atias, por um salário de 200 marcos anuais. A segunda aula, também por 200 marcos, ficou a cargo de R. Abraham Meatob, o qual tinha a tarefa de ensinar a "perasa em hebraico athe mea em ladino" ${ }^{34}$ A lição intermédia de "perasa ynteira em ladino athe profetas maiores e menores" ficaria a cargo de David Israel, por 300 marcos anuais, e por fim, a lição mais alta de "gemara" seria atribuída ao rabino da Nação, H. R. Mose Israel, por 425 marcos anuais. ${ }^{35}$

De modo a garantir que os professores cumprissem os seus deveres e os alunos "se aumentassem" nas suas lições, os parnassim de Talmud Torah tinham a obrigação de visitar a escola todos os dias de estudo, "cada hum seo dia, manha e tarde". ${ }^{36}$ Se por algum motivo um dos quais fosse obrigado a faltar, este teria de comunicar antecipadamente a sua ausência, de forma que outro administrador pudesse substituílo nas suas funções. ${ }^{37}$

16 Todas as terças-feiras, pela manhã, os professores eram incumbidos de "fazer repetir" aos talmidim (alunos) a lição da semana e aos mais pequenos, durante a tarde, a "parte da téfila"; tudo para que viessem a "saber e a diser na congregação beim e perfeitamente" as suas partes. ${ }^{38}$ Adicionalmente, ficava a seu cargo o ensino dos "bons custumes de curtizia" e garantir que todos, sem falta, falassem "com toda a modestia", de forma a que não houvesse neles "juramento nein palavra ruim, de ninhuma calidade". ${ }^{39}$ Teriam ainda a liberdade, se necessário, de castigar os talmidim, tanto dentro da escola como fora do seu perímetro, caso estes andassem pelas ruas inquietos.

Aos domingos antes do princípio do mês, eram incumbidos de examinarem os alunos na presença de todos os administradores, e de notar o que "cada hum augmenta" passando a lição mais alta ao que merecesse. ${ }^{40}$ Uma vez por ano, por altura do exame de Roshchodes Sivan, teriam de assinalar os talmidim que merecessem prémio e igualmente os que estivessem prontos a ser admitidos à "pernunciação e nos Tamim ou Accentos 
musicais". ${ }^{41}$ No valor de 50 marcos anuais, os prémios eram atribuídos por altura de Sebuot, numa cerimónia realizada dentro da sinagoga com honras especiais.

Os regulamentos destinavam-se igualmente aos pais das crianças ou "mayores de talmidim". Destes era esperado que não tratassem mal os professores da escola e que em tudo se comportassem com o devido "decoro e respeito", especialmente em caso de castigos aos seus filhos. ${ }^{42}$ Quaisquer queixas que tivessem relativamente aos professores deveriam ser comunicadas aos parnassim da instituição e nunca aos primeiros directamente. Quaisquer transgressões nesta área seriam correspondentemente castigadas pelo Mahamad.

Por sua vez, os professores tinham de acudir "com particular cuidado e continua vigilancia no ensino dos talmidim" e observar diária e escrupulosamente as horas das lições tal como estipuladas nos escamot da instituição. Nos dias normais, as aulas começavam por altura da reza de mincha, "mea hora depois de sahir de teffila", e a tarde, "uma hora e meia depois de teffila". ${ }^{43}$. As aulas tinham a duração diária de 6 horas, três de manha e três durante a tarde, exceto durante o inverno, no qual os dias de estudo tinham a duração de 5 horas.

20 Às sextas-feiras as lições tinham lugar somente durante a manhã, nomeadamente duas horas no verão e uma no inverno. Do mesmo modo, eram licenciadas as vésperas de Shabat, Páscoa (Pessach seni), 33 de Homer e 15 de Av, sendo obrigados a acudir ao período da manhã, durante uma hora. ${ }^{44}$ Nos dias de festa era-lhes concedida folga, assim como um dos dias inteiros de Hanuca, o qual ficaria à sua descrição. As folgas eram obrigatórias e não prorrogáveis, estando-lhes vedado o "empuxamento de qualquer dia para outro".

21 Por receio de represálias por parte dos locais, o Mahamad impunha, para além das já mencionadas, algumas restrições durante as chamadas "festas da terra". Durante a Páscoa, Pentecostes e Natal, os robissim ficavam livres no período da manhã, tendo de assistir somente duas horas durante a tarde, e isto "com a mayor quietasao que for possivel por evitar escandalo". 45

Todas as faltas por motivos de bodas, circuncisões e enterros eram-lhes expressamente proibidas, licenciando-se-lhes somente as ditas cerimónias em parentesco de primeiro grau ou outra "ocaziao tao urgente que julguem os tres parnassim ser [...] justo". ${ }^{46}$

Por seu lado os talmidim tinham o dever de se encontrarem nas escolas às horas indicadas assim como na esnoga da congregação geral para recitarem os salmos. Deles era esperado que se esforçassem diligentemente no cumprimento das suas tarefas escolares e que se mostrassem em tudo "muy apontadorhes", sem nunca dar motivos de queixa tanto aos professores como aos parnassim, especialmente durante os serviços sinagogais. ${ }^{47}$ Tais deveres eram-lhes regularmente relembrados tanto em ações como em palavras, e especialmente através de castigos regulares aos mais desobedientes. ${ }^{48}$

Para além de servirem como normas de ação, estas leis refletiam, até certo ponto, alguns dos desafios enfrentados pela comunidade no sistema educativo e a tentativa de abordá-los de forma preventiva. Tal é-nos sugerido, entre outros coisas, nas severas penas pecuniárias impostas aos professores em caso de falta (até 1 reichtaler) ou pelas restritivas regulações impostas aos pais nas suas relações com os professores. Tal como teremos oportunidade de ver mais adiante, esta preocupação não era de todo sem fundamento. 


\section{Evolução da Talmud Torah - Conflitos e Reformas entre 1652-1682}

Marcada por distúrbios entre o pessoal docente e seu comportamento progressivamente irregular, bem como indicações que sugeriam a "diminuição no ensino da talmud tora", o Mahamad é levado a impor, a 22 de dezembro de 1658, uma inspeção periódica sobre a referida instituição. ${ }^{49}$ Esta "escuta regular", tal como era chamada, deveria ser executada por um membro do Mahamad a cada dois meses, e destinava-se a controlar "o estado e o progresso" de cada aluno de modo a que, de acordo com a sua evolução, os professores fossem correspondentemente louvados ou repreendidos..$^{50}$

Alguns meses mais tarde, o hacham da comunidade, Izaque Jessurun, ofereceria voluntariamente os seus serviços, de forma a assistir na inspeção semanal que teria lugar dentro da Talmud Torah, todas as quintas-feiras. ${ }^{51}$ Somando-se à crescente frequência de inspeções e à presença de dignitários laicos e religiosos no perímetro escolar, a Talmud Torah seria palco, três anos depois, de uma nova e mais substancial reforma, desta feita do seu corpo administrativo. De forma a remediar o "pouco fruto" demonstrado pelos discípulos e o "descuido" com que os ministros acudiam, foram adicionados, para além dos dois administradores eleitos anualmente, mais três elementos à administração escolar: dois adjuntos e um superintendente. ${ }^{52}$ Estes teriam, juntamente com os parnassim, plena autoridade para "apenar e despidir os robissim e os moços que o merecerem", sem que para tal necessitassem do consentimento do Mahamad. ${ }^{53}$ Ao delegar maiores poderes nos parnassim da Talmud Torah, o Mahamad procurava efetivamente reforçar a autoridade dos mesmos perante os professores, agilizar a tomada de decisões dentro da instituição e promover o seu sentido de iniciativa em questões disciplinares e curriculares. Esperava-se, de forma geral, que estas alterações impulsionassem uma nova dinâmica na escola da comunidade, de forma que, progressivamente, esta começasse a corresponder às expectativas inicialmente depositadas.

27 Na prática, o corpo dos cinco administradores foi utilizado apenas durante dois anos entre setembro de 1661 e setembro de 1663 - sendo substituído daí em diante por três administradores até 1682 . Na origem desta alteração estaria porventura a inviabilidade prática em manter um corpo administrativo tão pesado, limitando-se a sua gestão a apenas três elementos. Os problemas que conduziam ao pouco rendimento e ao insucesso escolar por parte dos alunos não davam, porém, provas de se extinguirem. A 26 de setembro de 1665, o Mahamad introduziria novos incentivos como forma de motivar os alunos a aprenderem "com mais fervor", retomando o sistema dos prémios financeiros. ${ }^{54}$ Estes 30 marcos anuais deveriam ser divididos igualmente por todas as turmas da Talmud Torah e outorgados aos alunos mais dedicados por ocasião de uma cerimónia pública na sinagoga, acompanhada por louvores e honras.

Para além da diminuição dos padrões educacionais e o alegado fraco empenho demonstrado pelos professores, várias críticas tinham sido expressadas quanto à irregular assiduidade por parte dos últimos, a sua fraca pontualidade e mesmo, indícios dando conta de um forte descontentamento entre o corpo docente. ${ }^{55}$ Para além da "pouca saude" e "muita idade" que causava o "não pod[erem] asistir com regularidade ao ensino dos talmidim", ${ }^{56}$ vários indícios sugerem que este descontentamento pudesse estar ligado à recusa por parte do Mahamad em satisfazer as reivindicações salariais de 
muitos professores, levando a fortes desentendimentos entre as partes. Com efeito, tal como demonstrado nos livros protocolares, os baixos salários concedidos aos robissim desencadeariam reações adversas e protestos regulares por parte destes, como viria por exemplo a suceder em Abril de 1667, com o robi Mose Jessurun. ${ }^{57}$ Outras situações ainda, davam conta do agravamento das relações entre pais e professores e à forma como a autoridade dos últimos era progressivamente posta em causa por familiares responsáveis. Ainda que, como já visto anteriormente, os estatutos da Talmud Torah definissem escrupulosamente o contexto no qual se desenvolviam as relações entre pais e professores, esta provou ser menos que ideal em várias ocasiões, desestabilizando o regular funcionamento da escola e colocando em causa a autoridade institucional depositada nos professores. ${ }^{58} \mathrm{Um}$ dos casos mais extremos dar-se-ia a 17 de setembro de 1679, quando no seguimento de um castigo mais severo ordenado pelos parnassim, vários pais quebrariam o cadeado da Talmud Torah retirando os seus filhos à força do perímetro escolar. ${ }^{59}$

29 A perceção geral deixada por estes e outros incidentes na figura do professor enquanto subalterno impotente e largamente diminuído nas suas capacidades, acabaria por ser refletir na forma como estes eram tratados pelos próprios alunos, especialmente durante os serviços religiosos. A dado ponto, casos frequentes de revoltas e faltas de respeito entre os discípulos de $\mathrm{H}$. Mose Jessurun, levariam o Mahamad a conferir maior influência ao professor em causa, outorgando-lhe o poder de "expulsar da congregação todo aquele que desafiar a sua autoridade". ${ }^{60}$ Ainda que tardiamente, o Mahamad relembraria a toda a comunidade as funções, deveres e limites de cada interveniente no processo educacional (alunos, pais e professores), e a sua maior disponibilidade para, daí em diante, remediar quaisquer transgressões aos estatutos, naquilo que constituiria uma das mais importantes passagens dedicadas ao assunto:

“... havendo-se publicado nesta teba por diversas vezes o decoro e obediencia que devem ter os talmidim aos senhores parnassim de Talmud Torah y Rubissim e que os pais que querem ter seos filhos nas escolas devem na mesma ygualdade não maltrata-los por qualquer castigo que se de a ditos filhos y esperimentando oje o contrario se publica y se renova esta escama e o mahamad tem a seo cargo custa que qualquer desobediencia e desordem que se cometa contra os senhores parnassim y rubissim de Talmud Torah que se executara com todo o rigor". ${ }^{61}$

30 A incapacidade dos parnassim em corrigirem estes comportamentos e impor ordem dentro da instituição sugere por essa razão, não somente uma supervisão defeituosa da sua parte, mas sobretudo, e de forma mais geral, uma crise de autoridade que atravessou a instituição durante vários anos. A dada altura, o Mahamad seria obrigado a intervir, e numa reunião conjunta com os diretores e os professores escolares, chamaria a atenção para as suas obrigações em "acudir e asistir as horas de meldar (...) cada hum comforme sua calidade". ${ }^{62} \mathrm{Na}$ mesma, estipulava o Mahamad que, daí em diante, os salários dos docentes seriam pagos consoante o seu nível de assistência, descontando-se todas as faltas de acordo com o registo diário firmado pelos diretores da escola. ${ }^{63}$ Tais medidas apenas serviam para confirmar as expectativas dos professores quanto ao seu tratamento diferenciado dentro da comunidade, contribuindo para inflamar a sua convicção de que eram, aos olhos dos líderes portugueses, vistos como funcionários de segunda categoria.

31 De forma a assegurar maior continuidade na direção da instituição, decretaria o Mahamad a 23 de setembro de 1674, uma nova alteração aos estatutos da Talmud Torah. A nova ordem estipulava assim que, daí em diante, por altura da eleição anual, 
transitaria sempre um dos anteriores parnassim para a nova administração, de forma que pudesse informar "aos que de novo entrarem o modo que se tem no meldar e o estado de cada dicipulo". ${ }^{64}$ Relembrava ainda o Mahamad aos pais de talmidim que obrigassem os seus filhos "a ter o devido respeito aos seus mestres e os não tirem da escola por seus mestres os haverem castigado, advertindo que sahindo-se por essa cauza da escola nao sera depois admitido nella". ${ }^{65}$

Mostras de maior diligência e zelo por parte dos diretores da escola, levariam o próprio Mahamad a reforçar a sua presença nas ditas "escutas regulares" efetuadas à Talmud Torah. Poucos meses após o último decreto, os líderes comunitários demonstrariam a sua disponibilidade em redobrar a vigilância às escolas da Nação, ficando a cargo de cada parnassim o deslocar-se à instituição pelo menos uma vez por semana, de forma a ver se "acudem os robissim as suas horas e fazem o que devem a seus officios" 66 . Qualquer falta observada seria prontamente repreendida e condenada pelos mesmos.

A nova determinação demonstrada pelos sucessivos governos em melhorar o estado da Talmud Torah teria o seu ponto alto na "grande reformassao" de 3 de novembro de 1675, a qual, tal como o próprio nome indica, consistiu numa das maiores reformas operadas na instituição. ${ }^{67}$ Uma nova geração de professores substituiu os antigos, alguns por excessiva idade, outros por não parecerem "capazes para o ofício". Em tudo, a reestruturação obedecia a um novo ímpeto reformista que, desde logo, recebeu a aprovação unânime da junta plena e dos respetivos diretores da escola. 0 estado das finanças da escola era igualmente alvo de escrutínio: foi reafirmada a importância das nedavot anuais para o financiamento da instituição, assim como o adiantamento do "interes" concedido pelo Mahamad. ${ }^{68}$ Novas admoestações nas rezas semanais proferidas pelos hachamim chamariam a atenção dos congregantes para se alargarem nas promessas à Talmud Torah. ${ }^{69}$ Tais medidas tinham em mente, por outro lado, a cobrança atempada da espaca - a bolsa de estudo atribuída regularmente aos talmidim as quais, desde a integração da Ets Haim na tutela da Talmud Torah, representavam uma mais-valia para o progresso da instituição. ${ }^{70}$ Poucos anos após a introdução destas medidas, o Mahamad reconhecia finalmente os frutos de tal empreendimento, salientando através de uma passagem no livro protocolar, o grande "aumento das escolas da Talmud Torah" e a necessidade em continuar-se "este bem tao grande". ${ }^{71}$

\section{A Escola dos Alunos Pobres: a Ets Haim}

34 À parte das questões curriculares e educativas, que na sua grande maioria parecem ter seguido o padrão da instituição irmã - a Talmud Torah - a irmandade privada Ets Haim distinguia-se por providenciar aos alunos pobres da Nação os meios necessários para poderem concluir a sua educação básica e, eventualmente, prosseguir os seus estudos na yeshiva da congregação. Tal era feito, nomeadamente, através da concessão de bolsas de estudo, de contribuições mensais a estudantes pobres, assim como outros benefícios especialmente destinados a combater o abandono escolar e melhorar as perspetivas profissionais das camadas mais desfavorecidas da Nação. ${ }^{72}$ A constituição de turmas específicas para alunos pobres parece igualmente ter sido uma das funções da irmandade, a qual contratava o serviço de letrados e educadores da Nação, a baixo custo. Muito possivelmente, a orientação curricular modelava-se de acordo com a professada na comunidade portuguesa de Amesterdão, na instituição homónima da mesma cidade. Parcialmente secular, o programa contava com as disciplinas de 
aritmética, português e, possivelmente o latim; sendo contrabalançado com o estudo religioso da Torá, da tradição rabínica e do hebraico. ${ }^{73}$

Assim, o principal objetivo da Ets Haim era antes de tudo de cariz humanitário, isto é, assegurar as mesmas oportunidades educativas a todas as crianças da comunidade, independentemente da sua situação económica. Para além de constituir em si mesmo a observação de uma mitzvah, tal empreendimento remetia para a importância fundamental atribuída ao estudo da Torá no judaísmo, princípio que os judeus portugueses fizeram questão de conservar e promover entre si. Embora sem dúvida, o objetivo da instituição partisse de uma real preocupação social e económica, providenciando as condições para tirar da pobreza um sem número de famílias, esta servia igualmente um propósito implícito de controlo social e religioso. Através do estudo diário, da confraternização e da inculcação de uma disciplina de trabalho, a comunidade efetivamente levava a cabo a socialização de novas gerações de jovens pobres, muitos dos quais oriundos de um meio familiar iletrado e socioeconomicamente marginal.

\section{Conflitos metodológicos em torno da orientação pedagógica}

Embora a educação formal começasse na Talmud Torah aos seis anos, os pais tinham a obrigação de ensinar o hebraico aos seus filhos desde uma tenra idade (ou, em famílias abastadas, um tutor privado). ${ }^{74}$ Os parnassim dependiam assim fortemente deste compromisso por parte dos pais, dado que todas as crianças deveriam entrar na primeira lição da Talmud Torah com um conjunto básico de conhecimentos comuns. À medida que um crescente número de famílias pobres e sem formação começaram a afluir a Hamburgo, a quantidade de crianças não iniciadas a darem entrada na Talmud Torah começou a constituir um problema para os professores e diretores escolares, os quais em vista dos presentes estatutos eram obrigados a dissimular os regulamentos comunitários ou a excluí-las inteiramente das instituições de ensino.

Inquietos pela deficiente preparação com que muitos alunos iniciavam a escola, vários professores comunicariam ao Mahamad a sua conviç̧ão em como seria proveitoso ensinar o alefbet aos alunos de nível mais baixo, evitando desta forma a sua exclusão ou atraso no percurso escolar. ${ }^{75} \mathrm{~A}$ preocupação dos robissim não encontraria eco na posição do Mahamad, o qual se demonstraria intransigente para efetuar qualquer alteração ao currículo escolar. Segundo o Mahamad, se as crianças se mostravam mal preparadas, o problema residia em casa e não nas instituições da comunidade. Desta forma, a não ser que os jovens mostrassem provas concretas de conhecer o alfabeto hebraico, estariam impedidos de entrar na Talmud Torah, tal como sugere a seguinte passagem do livro protocolar: “(...) discursou-se sobre isto e resolveu o maamad não ensine nem aceite ditto pallache em sua escola menino que não saiba conhecer todas as letras e pontos do alefbet que athe este tempo os ensinasse seus pais em suas cazas ou os mandem aprender fora delas em demais aconto lhes esteja". ${ }^{76}$

A realidade, no entanto, encontraria a sua forma de levar o Mahamad a reconhecer o desfasamento entre os requisitos mínimos obrigatórios e o nível de conhecimento atingido pelos estudantes, aquando da sua entrada na Talmud Torah. Alvo de queixas por parte dos pais da comunidade sobre a aparente marginalização a que os seus filhos 
estavam a ser sujeitos, o Mahamad ver-se-ia obrigado a rever a sua posição inicial, baixando os critérios de entrada na escola. Desta feita os parnassim ordenavam ao professor R. Palache que passasse a "emsinar a todos os que forem levados a talmud thora e que a huns e outros, piquenos e grandez os da sua escola de licao cada dia [...] quanto o tempo lhe der lugar". ${ }^{77}$

39 A questão em torno da abertura das escolas da Nação a estudantes de fora foi igualmente sujeita a visões radicalmente divergentes sobre o propósito da educação comunitária. Ainda que durante um breve período de tempo as turmas da Talmud Torah estivessem abertas a alunos de origem asquenazita, esta prática foi a um dado momento abolida pelo Mahamad, o qual considerava que, para benefício dos talmidim da Nação, "convinha não admitir em Talmud Torah nenhu rapaz tudesco". ${ }^{78}$ Assim a partir de 11 de agosto de 1659, todos os rapazes que não fossem da Nação foram proibidos de assistir às aulas, à exceção dos que assistiam com os robissim $\mathrm{H}$. Mose Israel e David Israel. ${ }^{79}$ Com efeito, a tolerância dos educadores da comunidade face a estudantes de fora seria um indício significativo de uma diferente abordagem à educação, uma que esbarrava diretamente com as expectativas da liderança comunitária, mais particularista.

Quando a 9 de março de 1670, o professor R. Palache solicitou uma casa na congregação geral para dar aulas a alunos da Talmud Torah, o Mahamad recusaria a iniciativa, alegando que esta não se coadunava com as orientações da Nação ${ }^{80} \mathrm{Em}$ particular salientava o Mahamad o facto de Palache procurar dar aulas a alunos de diferentes fés, facto que seria contra os regulamentos da comunidade: "Pareceu bem advertir-lhe ao dito palache (...) como ao mahamad lhe viera a noticia hera sua intensao avir aqui a insinar alguns estudantes de diferente profissao do que a nosa y que não nos poderiamos vir a isso pelos danos que nisto já experimentamos (...) com que se escusa esta sua vinda e pareseu leer este termo ao ditto palache". ${ }^{81}$ Embora de forma geral os professores respeitassem as orientações comunitárias face à entrada de alunos de fora da Nação - fossem estes judeus asquenazitas ou cristãos protestantes - o assunto encontrar-se-ia ocasionalmente na ordem do dia em consequência de irregularidades pontuais, tal como revelado no caso de H.H. Jacob Benveniste: "chegou a noticia que hia um tudesco filho de R. Nachman a nossas escolas e por ser contra a escamot resolveu o maamad que se não consentisse e assi se chamou os parnassim de T.T. a que se advertiu e ordenou ao H.H. Jacob Benveniste que o não admita na escola". ${ }^{82}$

41 Tal como na produção e disseminação literária, eram os judeus levantinos e norte africanos que tomavam um papel especialmente preponderante nas instituições educativas das recém-formadas comunidades portuguesas, tanto pela sua alta cultura e forte enraizamento na tradição judaica, como pela carência de docentes portugueses habilitados ou disponíveis para exercerem o ofício. É aqui, no entanto, que surgem, mais uma vez, as diferenças consideráveis entre as linhas de orientação propostas pelos parnassim, os líderes comunitários, e por outro, as práticas empreendidas pelos docentes levantinos e norte africanos, os quais, por variadas ocasiões seriam obrigados a reformular os conteúdos curriculares e as práticas educacionais de forma a satisfazer as exigências da autoridade comunitária. Em Hamburgo estes conflitos foram caracterizados por uma componente especialmente ideológica, levando a ruturas e crises frequentes nas instituições de ensino, e dando origem àquilo que poderemos apelidar de um conflito cultural entre duas formas essencialmente divergentes de interpretar o modelo educativo e a transmissão do saber. 
42 Este desafio à autoridade dos diretores escolares e à hierarquia do sistema educativo constituía uma das mais fortes ameaças à integridade institucional da Talmud Torah. Muito embora o Mahamad tomasse qualquer desvio como um acto de transgressão, vários foram os casos de protesto e de insubmissão protagonizados pelos professores da escola. Quando a 10 de junho de 1657, o robi Joseph Palache apresentou ao Mahamad uma versão emendada dos estatutos escolares, na qual propunha alterações ao sistema educativo, encontraria por parte destes uma forte e veemente oposição. ${ }^{83}$ Indignados pelo que consideravam ser a atitude afrontosa de Palache, os diretores da escola expressaram ao Mahamad a sua indignação perante o que consideravam ser o comportamento subversivo e o "mau procedimento" demonstrado pelo professor. Condenando publicamente a atitude de R. Palache como uma "falta de respeito para com os diretores escolares e as suas graves faltas", o Mahamad ordena porém, de forma privada, uma inquirição em torno das suas propostas, com o intuito de reformar nelas "o que lhes parecer conveniente em benefício do geral e maior aumento da nossa santa ley" ${ }^{\prime 4}$. O facto de as emendas terem sido sujeitas à apreciação por parte dos rabinos da Nação e não imediatamente refutadas pelo Mahamad, revela não somente as implicações religiosas das matérias levantadas por Palache, como, de forma mais relevante, a importância atribuída às mesmas por parte das autoridades portuguesas.

Mais do que uma simples questão de orientação metodológica, a matéria tinha o poder de comprometer a autoridade da instituição e do Mahamad, ao apelar à lei e à tradição rabínica. Desta forma, testemunhamos, potencialmente, um dos poucos casos registados de um conflito cultural que medeia algumas das famílias não-conversas que tinham a seu cargo a educação e formação da comunidade, e por outro, a orientação educacional proposta pela liderança portuguesa, menos predisposta em termos tradicionais, e mais em sintonia com o meio cristão envolvente.

\section{Particularidades do modelo educativo em Hamburgo}

Importantes características distinguem a experiência educacional oferecida em Hamburgo face à de outros centros da diáspora portuguesa, em particular com Amesterdão. Em primeiro lugar, e tal como já visto anteriormente, a educação em Hamburgo encontrava-se subfinanciada e carenciada a nível de pessoal, situação que se torna evidente a partir das muitas referências a turmas superlotadas e professores sobrecarregados com múltiplas atividades educativas. Em segundo lugar, as instalações e recursos estavam longe de ser ideais, conjuntura que se devia não somente à falta de uma biblioteca pública ao estilo da Ets Haim em Amesterdão, ${ }^{85}$ mas também ao impacto da extrema vigilância exercida pela igreja luterana e aos seus efeitos na supressão da atividade religiosa (em particular nos ritos, cerimónias, observâncias públicas, assim como na produção literária). ${ }^{86} \mathrm{Em}$ terceiro lugar, a delicada situação política em Hamburgo, marcada por tensas relações com a população local e uma precária existência coletiva pode ter servido como uma das principais causas da sua fraca atratividade como centro de formação e atividade religiosa. Tomados em conjunto, tais factos ajudariam a explicar, juntamente com os problemas internos já assinalados, a fraca oferta de professores, a sua antiguidade e menor preparação, bem como, alegadamente, o seu fraco empenho na educação das crianças.

Finalmente, três características, que se prendem com a prática educativa propriamente dita, ilustram de forma singular os paradoxos e desafios da experiência didática em 
Hamburgo: a inclusão dos tudescos enquanto beneficiários do ensino primário (e mesmo, numa ocasião, estudantes de origem cristã), a diminuição dos padrões de admissão para entrada no ensino congregacional e, finalmente, os conflitos relativos à orientação pedagógica entre a liderança comunitária e o corpo docente. A importância destas ocorrências na definição da educação em Hamburgo não pode ser suficientemente realçada, dado que representariam, cada uma à sua maneira, um duro golpe na auto perceção de distinção e integridade que epitomava o ideal do modelo educativo português. Assim, ao contrário da história de sucesso que foi efetivamente Amesterdão, só a muito custo logrou Hamburgo manter a sua relevância a nível educacional, confirmando-se, no presente caso, a profunda discrepância entre o ideal e a realidade.

\section{Conclusão}

Tal como se pôde observar ao longo do presente artigo, as instituições educativas da comunidade portuguesa de Hamburgo como a Talmud Torah e a Ets Haim parecem ter sido especialmente marcadas por distúrbios entre o pessoal docente e a administração escolar ou entre os professores e os próprios pais. Em todo o caso, o ambiente dentro do corpo docente demonstrava não ser o mais harmonioso, facto que por sua vez influía no rendimento dos alunos e na sua aprendizagem. Conflitos em torno de questões salariais, pedagógicas, ou de matérias relativas à autoridade e influência dos vários intervenientes levariam o Mahamad a efectuar uma série de reformas tanto no corpo docente e administração escolar, como no sistema de incentivos a professores e alunos, relembrando a todos as funções, deveres e limites de cada um no processo educacional. Embora alguns destes problemas pudessem ser atribuídos a limitações financeiras, a sua perpetuação ao longo dos trinta anos considerados sugere graves lacunas no funcionamento da instituição, sugerindo tantos problemas de autoridade a nível interno, como uma conjuntura externa desfavorável à prática da atividade educativa. Assim, só a muito custo logrou o Mahamad satisfazer as expectativas inicialmente depositadas na instituição, sendo o resultado disso a nomeação em 1674 de Mose Jessurun para hacham geral da comunidade, o primeiro e único líder religioso exclusivamente formado nas instituições da comunidade durante o período estudado.

\section{BIBLIOGRAFIA}

\section{Archival Sources}

Staatsarchiv Hamburg [StAHH], Jüdische Gemeinden [JG] 993, Protokollbuch [PB] (1652-1682), Band I-II. 


\section{Bibliography and printed sources}

ALDEN, D., The making of an Enterprise: The Society of Jesus in Portugal, its Empire, and Beyond, 1540-1740, Stanford, Stanford University Press, 1996.

ARIÈS, Philippe, L'enfant et la Vie familiale sous l'Ancien Regime, Paris, Seuil, 1973.

BERNFELD, Tirtsah Levie, Poverty and Welfare among the Portuguese Jews in Early Modern Amsterdam, Portland, The Littman Library of Jewish Civilization, 2001, pp. 77-86.

BERNFELD, Tirtsah Levie, "Religious Life among Portuguese Women in Amsterdam's Golden Age", in The Religious Cultures of Dutch Jewry, eds. Yosef Kaplan and Dan Michman, Leiden, Brill, 2017, pp. 69-78.

BOER, Harm den, La Literatura Sefardí de Amsterdam, Alcalá de Henares, Instituto Internacional de Estudios Sefardíes y Andalusíes, 1995.

BRADEN, Jutta, Hamburger Judenpolitik im Zeitalter Lutherisher Ortodoxie: 1590-1710, Hamburg, Christians Verlag, 2001.

FEILCHANFELD, A., “Anfang und Blüthezeit der Portugiesengemeinde in Hamburg”, Zeitschrift des Vereins für Hamburgische Geschichte, 10 (1899), pp. 220-23.

FUKS, L., FUKS, R., “Introduction”, Studia Rosenthaliana, 9.2 (July 1975), pp. V-XII.

GOLDSIH, Matt, "The Amsterdam Portuguese Rabbinate in the Seventeenth Century: A unique Institution viewed from within and without", in Dutch Jews as Perceived by themselves and by Others: Proceedings of the Eighth International Symposium on the History of the Jews in the Netherlands, eds. Chaya Brasz and Yosef Kaplan, Leiden, Brill, 2001, pp. 7-19.

ISRAEL, Jonathan I., European Jewry in the Age of Mercantilism: 1550-1750, Oxford, The Littman Library of Jewish Civilization, 1985.

ISRAEL, Menasseh Ben, Thesouro dos Dinim que o povo de Israel he obrigado saber e observar, Amesterdão, 1645-47.

KAPLAN, Yosef, "Discipline, Dissent, and Communal Authority in the Western Sephardic Diaspora”, in The Cambridge History of Judaism: Vol. 7, The Early Modern World, 1500-1815, eds. Jonathan Karp and Adam Sutcliff, Cambridge, Cambridge University Press, 2018, pp. 402-403.

KELLENBENZ, Hermann, Sephardim an der unteren Elbe: ihre wirtschaftliche und politische Bedeutung vom Ende des 16. bis zum Beginn des 18. Jahrhunderts, Wiesbaden, F. Steiner, 1958.

LIEBERMAN, Julia R., "Childhood and Family among the Western Sephardim”, in Sephardi Family Life in the Early Modern Diaspora, ed. Julia R. Lieberman, Waltham, Brandeis University Press, 2011, pp. 129- 176.

LOPES, António, “A Educação em Portugal de D. João III à Expulsão dos Jesuítas em 1759”, Lusitania Sacra, 5 (1993,) pp. 13-41.

MARTINS, Hugo, A comunidade Judaico Portuguesa de Hamburgo entre 1652 e 1682, Diss. de Doutoramento, Lisboa, Faculdade de Letras da Universidade de Lisboa, 2018.

Ratio atq. Institutio studiorum Societatis Jesu. Superiorum permissu, Napoles, ex typographia T. Longi, 1598.

REILS, P. D. H., "Beiträge zur Ältesten Geschichte der Juden in Hamburg: aus den Acten des Staats- und des Ministerial-Archivs gesammelt und zusammengestellt", Zeitschrift des Vereins für Hamburgische Geschichte, 2 (1847), pp. 373-75. 
RODRIGUES, Francisco, História da Companhia de Jesus na Assistência de Portugal, 2 Vols., Porto, Livraria Apostolado da Imprensa 1931-50.

SCHILLING, Heinz, "Die Frühneuzeitliche Konfessionsmigration. Calvinisten und Sefardischen Juden im Vergleich“, in Religion und Mobilität: Zum Verhältnis von Raumbezogener Mobilität und religiöser Identitätsbildung im Frühneutzeitlichen Europa, eds. Henning P. Jürgens and Thomas Weller, Göttingen, Vandenhoeck \& Ruprecht, 2010, pp. 111-136.

SCLAR, David, "A Communal Tree of Life: Western Sephardic Jewry and the Library of the Ets Haim Yesiba in Early Modern Amsterdam”, Book History, 22 (2019), pp. 43-65.

STUDEMUND-HALÉVY, Michael, KOJ, Peter (eds.), Die Sefarden in Hamburg: zur Geschichte einer Minderheit, tomo I e II, Hamburg, Helmut Buske Verlag, 1994-1997.

STUDEMUND-HALÉVY, Michael, “Sephardische Bücher und Bibliotheken in Hamburg”, Menora: Jahrbuch für deutsch-jüdische Geschichte, Bodenheim, 1997, pp. 150-80.

SWETSCHINSKI, Daniel M., Reluctant Cosmopolitans: the Portuguese Jews of Seventeenth-Century Amsterdam, The Littman Library of Jewish Civilization, London, 2000.

VIVES, Juan Luis, Colloquia sive linguae Latinae exercitatio, Basileia, 1538.

WHALEY, Joachim, Religious Toleration and Social Change in Hamburg 1529-1819, Cambridge, Cambridge University Press, 1985.

WALLENBORN, Hiltrud, Bekehrungseifer, Judenangst und Handelsinteresse: Amsterdam, Hamburg und London als Ziele sefardischer Migration im 17. Jahrhundert, Hildesheim, Georg Olms Verlag, 2003.

\section{NOTAS}

1. Staatsarchiv Hamburg [StAHH], Jüdische Gemeinden [JG] 993, Protokollbuch [PB] (1652-1682), Band I-II [citado daqui em diante como "Livro da Nação"].

2. Sobre a comunidade judaico-portuguesa de Hamburgo, ver as seguintes obras: Hermann Kellenbenz, Sephardim an der unteren Elbe: ihre wirtschaftliche und politische Bedeutung vom Ende des 16. bis zum Beginn des 18. Jahrhunderts, Wiesbaden, F. Steiner, 1958; Joachim Whaley, Religious Toleration and Social Change in Hamburg 1529-1819, Cambridge, Cambridge University Press, 1985; Michael Studemund-Halévy, Peter Koj (Eds.), Die Sefarden in Hamburg: zur Geschichte einer Minderheit, tomo I e II, Hamburg, Helmut Buske Verlag, 1994-1997; Jutta Braden, Hamburger Judenpolitik im Zeitalter Lutherisher Ortodoxie: 1590-1710, Hamburg, Christians Verlag, 2001; Hugo Martins, A comunidade Judaico Portuguesa de Hamburgo entre 1652 e 1682, Diss. de Doutoramento, Lisboa, Faculdade de Letras da Universidade de Lisboa, 2018.

3. Joachim Whaley, Religious Toleration..., p. 73.

4. Uma transcrição integral do contrato de 1612 encontra-se editada em P. D. H. Reils, "Beiträge zur Ältesten Geschichte der Juden in Hamburg: aus den Acten des Staats- und des MinisterialArchivs gesammelt und zusammengestellt", Zeitschrift des Vereins für Hamburgische Geschichte, 2 (1847), pp. 373-75; o original encontra-se parcialmente em StAHH, Senat, Cl. VII, Lit. Hf, Nr. 5, Vol. 3a, Fasc. 1 e 4.

5. A. Feilchenfeld, “Anfang und Blüthezeit der Portugiesengemeinde in Hamburg”, Zeitschrift des Vereins für Hamburgische Geschichte, 10 (1899), p. 220-23.

6. Jonathan I. Israel, European Jewry in the Age of Mercantilism: 1550-1750, Oxford, The Littman Library of Jewish Civilization, 1985, p. 75. 
7. Hiltrud Wallenborn, Bekehrungseifer, Judenangst und Handelsinteresse: Amsterdam, Hamburg und London als Ziele sefardischer Migration im 17. Jahrhundert, Hildesheim, Georg Olms Verlag, 2003, p. 339.

8. $O$ acordo da unificação assim como os estatutos fundadores da nova congregação geral Bet Israel podem encontrar-se transcritos em: Hugo Martins, A comunidade Judaico Portuguesa de Hamburgo..., pp. 293-99.

9. Esta estimativa baseia-se nas listas fiscais do direito da Nação, incluindo todos os marginais, forasteiros, assim como, para todos os efeitos, os tudescos a serviço da Nação, até à sua independência em 1671. Livro da Nação, tomo I, pp. 32, 70-71, 114-15.

10. O mais importante estudo sobre a actividade económica, política e diplomática dos judeus portugueses de Hamburgo continua a ser o de Hermann Kellenbenz, Sephardim an der unteren Elbe, Wiesbaden, Franz Steiner Verlag, 1958.

11. Michael Studemund-Halévy, "Sephardische Bücher und Bibliotheken in Hamburg", Menora: Jahrbuch für deutsch-jüdische Geschichte, Bodenheim, 1997, pp. 150-80.

12. Jutta Braden, Hamburger Judenpolitik..., pp. 262-276.

13. Joachim Whaley, Religious Toleration..., p. 79.

14. Hermann Kellenbenz, Sephardim an der Unteren Elbe..., pp. 53-54.

15. A liderança da comunidade portuguesa de Hamburgo ficava a cargo de um conselho eleito anualmente - o Mahamad - o qual era investido de máxima autoridade para administrar a comunidade e gerir todas as áreas subordinadas à sua jurisdição.

16. Livro da Nação, tomo I, p. 125.

17. Daniel M. Swetschinski, Reluctant Cosmopolitans: the Portuguese Jews of Seventeenth-Century Amsterdam, The Littman Library of Jewish Civilization, London, 2000, p. 210.

18. L. Fuchs and R. Fuchs, "Introduction", Studia Rosenthaliana, 9- 2 (July, 1975), p. vi.

19. Matt Goldish, "The Amsterdam Portuguese Rabbinate in the Seventeenth Century: A unique Institution viewed from within and without", in Dutch Jews as Perceived by themselves and by Others: Proceedings of the Eighth International Symposium on the History of the Jews in the Netherlands, eds. Chaya Brasz and Yosef Kaplan, Leiden, Brill, 2001, pp. 12-15.

20. António Lopes, “A Educação em Portugal de D. João III à Expulsão dos Jesuítas em 1759”, Lusitania Sacra, 5 (1993,) pp. 13-41.

21. Francisco Rodrigues, História da Companhia de Jesus na Assistência de Portugal, 2 Vols., Porto, Livraria Apostolado da Imprensa 1931-50; D. Alden, The making of an Enterprise: The Society of Jesus in Portugal, its Empire, and Beyond, 1540-1740, Stanford, Stanford University Press, 1996.

22. Ratio atq. Institutio studiorum Societatis Jesu. Superiorum permissu, Napoles, ex typographia T. Longi, 1598 [i.e., 1599].

23. Juan Luis Vives, Colloquia sive linguae Latinae exercitatio, Basileia, 1538.

24. Philippe Ariès, L'enfant et la Vie familiale sous l'Ancien Regime, Paris, Seuil, 1973.

25. Aboab, "Documentos para todo estado e ydade", fos. 6-7, Amesterdão, Livraria Ets HaimMontezinos, MS 48 D9.

26. Menasseh Ben Israel, Thesouro dos Dinim que o povo de Israel he obrigado saber e observar, Amesterdão, 1645-47; para uma análise desta obra no contexto da infância e da vida familiar sefardita ver: Julia R. Lieberman, "Childhood and Family among the Western Sephardim", in Sephardi Family Life in the Early Modern Diaspora, ed. Julia R. Lieberman, Waltham, , Brandeis University Press, 2011, pp. 129-176.

27. Sobre a educação das mulheres na comunidade judaico-portuguesa de Amesterdão ver: Tirtsah Levie Bernfeld, “Religious Life among Portuguese Women in Amsterdam's Golden Age”, in The Religious Cultures of Dutch Jewry, eds. Yosef Kaplan and Dan Michman, Leiden, Brill, 2017, pp. 69-78.

28. Yosef Kaplan, "Discipline, Dissent, and Communal Authority in the Western Sephardic Diaspora", in The Cambridge History of Judaism: Vol. 7, The Early Modern World, 1500-1815, eds. 
Jonathan Karp and Adam Sutcliff, Cambridge, Cambridge University Press, 2018, pp. 402-403; Tirtsah Levie Bernfeld, Poverty and Welfare among the Portuguese Jews in Early Modern Amsterdam, Portland, The Littman Library of Jewish Civilization, 2001, pp. 77-86.

29. Heinz Schilling, "Die Frühneuzeitliche Konfessionsmigration. Calvinisten und Sefardischen Juden im Vergleich, in Religion und Mobilität: Zum Verhältnis von Raumbezogener Mobilität und religiöser Identitätsbildung im Frühneutzeitlichen Europa, eds. Henning P. Jürgens and Thomas Weller, Göttingen, Vandenhoeck \& Ruprecht, 2010, p. 131.

30. Sobre a produção literária sefardita e as suas inluências clássicas e cristãs ver: Harm den Boer, La Literatura Sefardí de Amsterdam, Alcalá de Henares, Instituto Internacional de Estudios Sefardíes y Andalusíes, 1995.

31. Livro da Nação, tomo I, pp. 14-17.

32. Livro da Nação, tomo I, pp. 14-17.

33. "Se mandarão chamar os Parnasim de Talmud Torah e se lhes encomendou o cuidado que devem ter de fazer observar todas as ascamott que estao notadaz neste Livro aserca de Talmud Torah no anno 5413". Livro da Nação, tomo I, p. 122.

34. Livro da Nação, tomo I, p. 10.

35. Livro da Nação, tomo I, p. 10.

36. Livro da Nação, tomo I, p. 15.

37. “ (...) e quando por urgente ocazião não puder aquelle aqueim tocar seo dia pedira a hum de seos companheiros que o fassa por elle, tante pera que vejao que os senhores Robiçim cumpreim com sua obrigação como pera que os Talmidim venhao promptamente e se augmentem em suas lisões e que com sua presensa não aja em nada falta". Livro da Nação, tomo I, p. 15.

38. Livro da Nação, tomo I, p. 15.

39. Livro da Nação, tomo I, p. 15.

40. Livro da Nação, tomo I, p. 15.

41. Livro da Nação, tomo I, p. 15.

42. "Que os pais ou Mayores de Talmidim não tratarão mal aos senores robicim pellos averem castigado ou outra cousa alguma antes se asentara muito a que lhes tenhao o decoro e respeito devido, e ainda animando-os para que com mais vontade os ensinem e quando delles tenhão algua queixa a dirão aos senhores Parnasim que elles acudirão a ysso e quando não baste e fizerem o contrario, os senhores sette do governo geral tomarão a seo cargo apenarem a queim nisto incorrer, e todos os talmidim aynda aqueles que não foreim da sua escola ou lisão obedecerão e respeitarão a todos os dittos senhores robisim como lhes he divido". Livro da Nação, tomo I, p. 15.

43. Livro da Nação, tomo I, p. 14.

44. Livro da Nação, tomo I, p. 16.

45. Livro da Nação, tomo I, p. 16.

46. Livro da Nação, tomo I, p. 17.

47. "Que os talmidim que faltarem de vir a escola as horas limitadas como tambeim a congregação e não estiverem nella muy quietos a dizer suas sefilot nas quais estarão muy promptamente advertidos por que são o fundamento para tudo o mais e como de tanta ymportancia ao servisso divino, e ao decoro que se deve a sua santa Ley e educação que demos [...] em nossas oracons se tera nisso particular cuidado (...)". Livro da Nação, tomo I, p. 14.

48. “(...) e se lhes dara seo castigo conforme merecerem sem respeitar nem exceptuar algum para que temão e andem nisto muy apontadorhes". Livro da Nação, tomo I, p. 14.

49. "Conhecendo o mahamad o quanto vay en diminuição o ensino de Talmud Torah e que se lhes ocorre tanta obrigação de por os olhos com muito cuidado nesta misva sendo a maior que temos entre nós, e aquela para mais que todas pode neste nosso cativeiro sustentar-nos se determinou que cada doiz mezes se fassa escuta geral de todos os talmidim e assistira della hua pessoa do maamad em companhia dos parnassim de Talmud Torah e se fara com toda a vigilancia e 
diligencia possivel pondo por nota o estado de cada talmid, para se poder ver na escuta seguinte o que cada hu avança e louvar ou repreender aos rubissim conforme aquillo que acharem e querem el dio que com isso va esta misva em muito aumento". Livro da Nação, tomo I, p. 125.

50. Livro da Nação, tomo I, p. 14.

51. Livro da Nação, tomo I, p. 153.

52. "Se fez nova eleição e se acrescentou aos parnassim de talmud torah tres pessoas mais por ver o pouco fruto que fazem os discipulos e o descuido com que os ministros acudem e para remediar isto pareceu ao maamad nomear dous adjuntos mais e ao H. Ishack Jessurun por supertendente de talmud torah e os tres com os dous parnassim terão plena autoridade para apenar e despidir os robissim e os moços que o merecerem sem que para isso se necessite de consentimento do maamad que para tudo lhe concede amplo poder". Livro da Nação, tomo I, p. 210.

53. Livro da Nação, tomo I, p. 210.

54. Livro da Nação, tomo I, p. 296.

55. Livro da Nação, tomo II, p. 41.

56. Livro da Nação, tomo II, p. 38.

57. Jessurun entraria em rota de colisão com o Mahamad após se recusar a desempenhar tarefas na sinagoga e na Talmud Torah. A disputa atingiu o ápice quando Jessurun abandonou a sua turma de profetas, deixando todos os seus alunos desinformados e causando graves distúrbios dentro da escola. A gravidade da situação levaria o Mahamad a fazer um ultimato, obrigando-o sob ameaça de despedimento, a aceitar um conjunto de novas condições estipuladas com a comunidade. O Mahamad relembrava que anteriores professores tinham "humildemente" aceite salários mais baixos por maior quantidade de trabalho, e que ele próprio tinha recebido um aumento com base na sua recusa em aceitar as promessas anuais. O Mahamad advertia, adicionalmente, que não aceitaria sob nenhuma circunstância, a sua "insuprivel altives e desprezo", nem permitiria que o seu comportamento auto-indulgente governasse o destino da escola e o avanço dos seus alunos. Livro da Nação, I, pp. 345-47.

58. A maioria dos casos seguia um padrão típico: a repreensão de um aluno na escola provocava a indignação de um familiar responsável, que imbuído de paixão descarregava publicamente sobre o professor implicado. A "insolencia” de Daniel Habilho para com o robi Abraham Meatob valerlhe-ia, por exemplo, uma retractação pública e uma multa de 2 reichtalers para a bolsa geral. 0 Mahamad salientava a ligeireza do castigo em virtude de ser Habilho "homem de grandes responsabilidades". Livro da Nação, tomo I, p. 81.

59. Obrigado a relembrar a toda a congregação os limites da autoridade parental, o Mahamad secundaria tal aviso com uma pena exemplar atribuída aos responsáveis de tal incidente: Moseh Bravo e Jacob Bravo, castigados em 3 e 1 marcos, respectivamente, o primeiro por ter quebrado o cadeado e o segundo por se ter alterado com um dos professores; e ainda Jacob Belmonte por ter dado "mas palabras" ao parnassim, pagando de multa 6 marcos. Livro da Nação, tomo II, p. 247.

60. Livro da Nação, tomo I, p. 492.

61. Livro da Nação, tomo II, p. 247.

62. Livro da Nação, tomo II, p. 38.

63. "de oje em diante não podera o tizoureiro pagar salario nenhu a dittos robisim sem primeiro trazerem escrito firmado para os tres parnassim de talmud tora e registado por o parnas prezidente da nação de haverem asistido bem as suas horas na escola e havendo algua falta se lhes descontara". Livro da Nação, tomo II, pp. 38-39.

64. Livro da Nação, tomo II, p. 42a.

65. Livro da Nação, tomo II, p. 42a.

66. Livro da Nação, tomo II, p. 76.

67. A "grande reformassão" deu-se, nomeadamente, ao nível do corpo docente, com a contratação e despedimento de professores, assim como através de uma reorganização das turmas e do seu conteúdo programático. Livro da Nação, tomo II, pp. 87-88. 
68. Livro da Nação, tomo II, p. 258.

69. Livro da Nação, tomo II, p. 258-59

70. Livro da Nação, tomo I, p. 529.

71. Livro da Nação, tomo II, p. 337.

72. Na ausência de fontes fontes relativas ao funcionamento interno da Ets Haim em Hamburgo, veja-se a análise para a instituição análoga em Amesterdão, a partir da qual se inspirou a primeira: Tirtsah Levie Bernfeld, Poverty and Welfare among the Portuguese Jews..., pp. 97-102.

73. Pagamento a Samuel de Leão para ensinar os estudantes pobres a escrever: "ordenou o mamat que se dessem 3 reicthalers a Samuel de Leao para o cuidado que tem com o ensino de escrever dos mossos pobres de nosa nasao”. Livro da Nação, tomo II, p. 353.

74. Julia R. Lieberman, “Childhood and Family among the Western Sephardim...", pp. 158-59.

75. Livro da Nação, tomo I, p. 295.

76. Livro da Nação, tomo I, p. 295.

77. Livro da Nação, tomo I, p. 300.

78. Livro da Nação, tomo I, p. 152.

79. Livro da Nação, tomo I, p. 152.

80. Livro da Nação, tomo I, p. 456.

81. Livro da Nação, tomo I, p. 456.

82. Livro da Nação, tomo II, p. 145.

83. Livro da Nação, tomo I, p. 92.

84. Livro da Nação, tomo I, p. 92.

85. Sobre a importância da livraria Ets Haim em Amesterdão, ver: David Sclar, "A Communal Tree of Life: Western Sephardic Jewry and the Library of the Ets Haim Yesiba in Early Modern Amsterdam", Book History, 22 (2019), pp. 43-65.

86. Sobre este aspecto veja-se: Hugo Martins, A Comunidade Judaico-Portuguesa..., pp. 239-245.

\section{RESUMOS}

O presente estudo centra-se na temática da educação na comunidade judaico-portuguesa de Hamburgo entre 1652 e 1682. Tomando por base os livros protocolares da comunidade escritos durante o período, serão analisadas instituições fundamentais a nível educativo, tal como a Talmud Torah e a Ets Haim e aprofundadas as suas contribuições na formação dos jovens membros da comunidade. Em particular serão investigados os estatutos congregacionais relativos às instituições educativas e a evolução destas ao longo dos trinta anos considerados, tendo especial atenção às dinâmicas entre os seus vários intervenientes - alunos, professores administradores - assim como às principais reformas e conflitos a marcarem a sua história. Ao aprofundar a natureza, âmbito e actuação destas instituições o presente estudo pretende recuperar uma dimensão até então pouco conhecida da história desta comunidade, naquele que é muito possivelmente, um dos períodos mais importantes do seu desenvolvimento.

The current study focuses on the theme of education in the Portuguese-Jewish community of Hamburg between 1652 and 1682. Taking as a reference the protocol books of the community written during the period, the study will analyse fundamental educational institutions such as the Talmud Torah and the Ets Haim, and assess their contributions in the formation of young members of the community. Particular attention will be dedicated to congregational statutes 
relative to educational institutions and their evolution along the thirty years considered, specifically with regards to the dynamics involved among the various parties - students, professors and administrators - as well as the main reforms and conflicts shaping the history of the community. By analysing the nature, scope and intervention of these institutions, the current article pretends to recover what remains a little-known dimension of the history of this community, in that which is, arguably, one of the most important periods of its development.

\section{ÍNDICE}

Keywords: Jewish Community, Portuguese Nation, Hamburg, Education, Sephardic Diaspora Palavras-chave: Comunidade Judaica, Nação Portuguesa, Hamburgo, Educação, Diáspora Sefardita

\section{AUTOR}

\section{HUGO MARTINS}

Centro de História, Faculdade de Letras, Universidade de Lisboa, Portugal hugo.fcc.martins[at]gmail.com 